\title{
Human Rights and American Traditions
}

\author{
Alexandru Boboc-Cojocaru
}

\begin{abstract}
Since the beginning, the United States has recognized and respected the rights of individuals. Besides serving as custodian of a rich historical and political tradition on human rights, the United States has contributed greatly to the crystallization of International human rights legislation through the establishment of the United Nations Organization and the development of the United Nations Charter. From my perspective, the real dilemma faced by the United States has included so far the issue of solving specific problems related to human rights, the way in which human rights considerations combine with other factors of foreign policy and the way of creating a sustainable public consensus in support of their policy on the realm of human rights. In my opinion it is unlikely that these efforts should ever be entirely solved successfully. That's why, in this paper, I try to analyze the correlation between moral and pragmatic components of the U.S. policy on human rights in the last 40 years.
\end{abstract}

Index Terms-Human rights, United States of America, foreign policy, political culture, constitutional tradition.

\section{INTRODUCTION}

Since the beginning, the United States has recognized and respected the rights of individuals. The "Declaration of Independence" begins with the famous list of "certain inalienable rights" that are "self-evident": the right to "life, liberty and the pursuit of happiness". The American constitutional code states that the purpose of the government is to "secure the blessings of liberty to ourselves and our posterity", while the first 10 constitutional amendments designed to clarify certain rights and which are not mentioned in the Constitution have become the "Bill of Rights". The key events in the history of the American nation - the War of Independence, the War of Secession, the two World Wars, the civil rights struggle of the " 60 s helped to strengthen the freedom and the rights of individuals in the United States and abroad.

The United States was born in the revolutionary struggle which was largely animated by the desire of the colonists to restore and protect their rights against arbitrary state power. The first leaders of the American nation believed that all individuals had certain natural and inalienable rights. Such natural rights are not granted by a government to the people and they cannot be cancelled by the government either: they are attributes of all human beings. As the British philosopher John Locke explains, the purpose of the government is to secure liberty. In fact, after they had been direct witnesses to the ravages caused by tyranny, the

Manuscript received December 20, 2012; revised February 28, 2013.

Alexandru Boboc-Cojocaru is with the Faculty of History, "Alexandru Ioan Cuza” University, Iasi, Romania (e-mail: alex78iasi@yahoo.com). founders of the American nation decided to create a society where systematic violations of the natural rights of individuals by the state could not occur. Influenced by the work of philosophers such as Locke, Montesquieu and Hume, they also believed that it was foolish to rely solely on the goodness of the human nature or on an enlightened policy promoted by a single leader. Therefore, the only reliable way which could ensure the exclusion of tyranny and abuse of the state power was the establishment of a fully democratic regime, endowed with a system of controls and counterweight.

In addition, a sustainable conviction of nation's founders and their successors was that the great ideals of freedom, democracy and human rights were not reserved only for Americans. The belief in the universal nature of the American experience was born neither from a cultural arrogance nor from the desire to impose the views of the United States to the rest of the world. It reflected the belief that the young society with a democratic political system "par excellence" and with no interest in the ruthless struggle for power that was taking place at that time in Europe was, as the Puritan pastor John Winthrop said, "a city on a hill".

The belief in the universality of human rights is reflected in the key documents of the early history of the United States. For example, the Declaration of Independence proclaims as ineluctable the fact "that all men are created equal, that they are endowed by their Creator with certain unalienable rights, that among these are Life, Liberty and the pursuit of Happiness". The concept of protecting the natural rights of individuals is present in many constitutions of the Member States of the federation and in the Bill of Rights, which is part of the U.S. constitutional code. These documents provide perhaps the most vigorous and lively defence of the concept of human dignity, democracy and freedom. Their universality was considered an almost selfevident assumption, which made Thomas Jefferson state, in a letter to James Madison, in 1787, that "a Declaration of Rights is what people are entitled to (as defence) against every government on earth".

\section{THE PREMISES OF THE MODERN ERA}

Over the years, the United States spoke strongly against the oppression in other countries, from the pogroms in Russia to the Ottoman atrocities against Armenians and Slavs. The multiethnic composition of the U.S. society and the main concerns of many ethnic groups of the U.S. population regarding the conditions in their home countries contributed to the United States' criticism of the human rights violations in other countries [1].

In the words of Thomas Jefferson, "the Empire of Liberty" in the United States was meant to serve the cause of 
freedom throughout the world and to help those who were struggling to promote it. This was interwoven with an inborn American optimism regarding the human condition and the idea that even complex international problems would eventually prove to be solvable in rational ways. However, other Americans had a more restricted perspective regarding the adequate policy of the United States. John Quincy Adams, who served as foreign minister between 1817 and 1825, said: "We are friends of liberty everywhere, but custodians only of our own (freedom)". This was the beginning of the controversy about the limits and appropriate uses of power in the United States. Thus, the rich cultural, constitutional and political traditions of the U.S. provide a hospitable environment to a foreign policy that contained the concern on the situation of human rights in other countries.

However, it would be too simplistic to claim that the political traditions of the United States can automatically be translated into an active and consistent policy regarding human rights. For example, they are characterized by a moralistic tendency and a certain confusion regarding international relations, which are largely dominated by the power policy, as well as the internal relations, which are organized on the principles of the rule of law. To some extent, an awareness of geopolitical invulnerability and a long isolation from the effervescence of the international policy emphasized the tendency to adopt moralistic positions related to the foreign policy [2].

Another unfortunate feature of the American political culture is the tendency of geopolitical withdrawal and isolationism, regularly promoted by a significant part of the American elite and by the electorate in general. A quite interesting aspect is that America's concerns on the human rights appear to be consistent with the isolationist element of the American tradition. Thus, the issues of human rights and the deviations from democracy exhibited in many countries were zealously exploited in the argumentation of the isolationism's followers. They claimed that the United States should not engage in foreign policy initiatives which were inherently immoral, and they had to limit their international efforts to maintaining the relations with the few countries with authentically democratic systems.

However, despite this apparent consistency between isolationism and the concerns about moral issues related to human rights, the promoters of an active foreign policy correctly noted that isolationism benefited from great support just when the ethical components of the U.S. foreign policy were ignored [3]. Thus, as publicist Charles Krauthammer noted, promoting freedom became an indispensable foundation of any active international position adopted by the United States.

Throughout history, the human rights considerations have played an important role in shaping the foreign policy initiatives of the United States. Examples include: Woodrow Wilson's "14 points" announced the end of World War I, Briand-Kellogg Pact, proposed by the United States and France in the '20s, and the establishment of the United Nations Organization. In the early years of the eighth decade, the factors related to human rights began to play a more visible role in everyday's foreign policy of the U.S.

The Congress adopted thematic human rights clauses.
One of the earliest examples is the "Jackson-Vanik" amendment in 1974, according to which countries with economies that "do not follow the market principles" and with restrictions on emigration of their citizens are not admissible as business partners that receive the most favourable customs treatment from the United States. The U.S. government also played a role in creating this new atmosphere of attention paid to human rights during the meeting for signing the "Helsinki Agreement" in 1975.

These tidal movements on human rights of the U.S. policy have been supported and institutionalized by an active community devoted to human rights and composed of legislators and people from the private economic sector. Serving the cause of human rights has become an important element of the U.S. foreign policy. This element is firmly rooted in the American political culture and constitutional tradition and generally enjoys strong bipartite support in the Congress and among the U.S. population in general[4]. Therefore, the debate focusing on whether it is desirable for the United States to pay attention to human rights considerations in developing its foreign policy or to pursue a version of pure Realpolitik is intellectually sterile and irrelevant in a practical sense.

The real dilemma faced by the United States has included so far the issue of solving specific problems related to human rights, the way in which human rights considerations combine with other factors of foreign policy and the way of creating a sustainable public consensus in support of their policy on the realm of human rights. It is unlikely that these efforts should ever be entirely solved successfully.

\section{THE PRAGMATISM - AN IMPERATIVE}

The policy related to human rights seems to enjoy the bipartite support just on a somewhat abstract level. For example, while the promotion of the cause of human rights generally enjoyed popularity, the discussions that took place in America on the topic of human rights are still characterized by a considerable degree of confusion. During the Carter administration, for example, there was an extensive effort for the equivalation of civic and political rights to social and economic rights. Yet, the traditional American concept is that political rights, as a reflection of the laws of nature, provide a vital foundation for any democratic society [5].

The traditional liberal political philosophy also referred mainly to the individual's rights against the State (which former Supreme Court Judge Louis Brandeis once called "the fundamental human right to be left alone"), the human right to enjoy the fruits of their labour and to live their lives as they wish, as long as they do not unduly infringe the rights of others. In the U.S. constitutional tradition, these rights are so sacred that they outperform the political rights in some important respects. Consequently, even the desire of a majority expressed through a democratic process may not restrict certain fundamental individual rights. However, it is inevitable that an unjustified emphasis on economic and social rights, considered as entitlements, should conflict with the very essence of the American political tradition, as any attempt to secure such rights directly involves mobilizing all of society's resources, leading eventually to a 
system of government with unlimited power or which can even be totalitarian.

Besides serving as custodian of a rich historical and political tradition on human rights, the United States has contributed greatly to the crystallization of international human rights legislation through the establishment of the United Nations Organization and the development of the United Nations Charter. In fact, one of the first and most important documents - the Universal Declaration of Human Rights adopted by the UN General Assembly in 1948 - was developed under the guidance of the U.S. representative to the UN Commission on Human Rights, Eleanor Roosevelt, wife of U.S. President.

Although the U.S. policy on human rights in many ways shows a considerable degree of continuity, it has undergone significant transformation over the past nearly 40 years. But here it must be said that the real changes in U.S. human rights policy differ from those criticized by many commentators. A wrong idea which is often heard is that the Carter administration led a vigorous policy in this area, and the government led by Ronald Reagan started with the intention to give up the active promotion of human rights causes. The Reagan administration started with the belief that it was necessary to learn both from the mistakes and from the success of the previous government. It realized that even the idealistic pursuit of objectives requires pragmatism and prudent application of political decisions. Although it intended to increase the power and the influence of the United States, the Reagan administration realized that the U.S. ability to lead democratic change in the world was not unlimited.

In preparing its policy on human rights, the Reagan-Bush administration addressed five main issues. The first attempts to answer the question "to what extent and how quickly should pressures be applied in order to determine an authoritarian regime to resort to reform?" There are no standardized recipes. Rather, what is required is a differentiated policy that treats each country on account of all relevant facts and circumstances. Thus, a country with a vigorous democratic tradition and a government willing to weigh reform possibilities should be encouraged, both by positive incentives and by punitive measures so that it accelerate change. A pro-American authoritarian regime in conflict with insurgent forces must be encouraged to liberalize its policy but without being subjected to pressures (through sanctions from the United States) capable of leading to its downfall. Between these two extremes there is an infinite variety of situations that need to be addressed through a pragmatic use of conclusions of adequate analyses of events and developments in each country. The Reagan administration based its efforts to encourage democratic change on this differentiated strategy in its policy for Brazil, Salvador, Honduras and South Korea [6].

"How to handle the crisis of a repressive regime" - this is a second problem. In such cases, prompt U.S. action is the key to success. The U.S. needs to know if there is a viable democratic opposition or an anti-democratic force; if both elements are present, the United States must know which one is more likely to emerge victorious from the conflict. All these precautions do not mean that the United States should never encourage the elimination of a repressive regime.
"How to create a balance between the attention paid to individual cases regarding human rights and the efforts to boost reforms with a vast horizon" - this is the third category of problems. In general, the United States must simultaneously pursue goals related to these two aspects of the policy on human rights. As noted by the political analyst Joshua Muravchik, "the struggle for human rights is far from... not being related to political systems; it is essentially a fight on political systems". "This battle", he continued, "cannot simply be an ongoing effort to stigmatize an infinite number of individual cases in which (human rights) are violated. It should instead pursue building political systems with embedded ideas of human rights and the means of protection of these rights. "

The fourth issue is related to the "relationship between human rights and other determinants of the U.S. foreign policy". Those who criticize the U.S. policy on human rights often place the emphasis on the decisions of providing military or economic aid to countries whose record on human rights is less than perfect. According to these critics, such decisions prove that the U.S. is not serious about the objective of promoting human rights. Obviously, this notion is simplistic and entirely wrong. Human rights considerations are an important factor in determining the course of the relations of the U.S. with other countries - but not the only factor.

However, to be successful in defending human rights, the United States must act realistically and cautiously. It should not always expect immediate results but must unswervingly encourage permanent improvement - however modest. Obviously, we cannot expect a country torn by civil war or where the state fights terrorists with beliefs of the left or the right wing trying to overthrow an early democratic regime to improve human rights as promptly as a country that enjoys political and economic peace [7]. However, certain type of abuse (torture, for example) is so horrible that no state reason can justify it in any circumstances and must be vigorously condemned without exception.

Morally, it is also necessary to overcome the borders of the one-dimensional ethics and to weigh the costs and benefits of the actions taken by the United States. For example, the destabilization of a repressive or authoritarian regime can bring to power an even more repressive regime which is also more durable - of totalitarian nature. If we do not take into account the limits of the U.S. influence as well as the consequences of the actions taken, the result can be a human rights policy that is rich in moral principles but poor in positive, concrete results. However, for a country that consistently commits serious violations of human rights, the United States must use firm conviction, even though currently there seems to be no chance of success.

The last issue concerns the "means of achieving the U.S. objectives regarding human rights". Many people believe that the United States can achieve its objectives related to human rights only through official representation and pressures put openly. Yet, experience shows that, to achieve its goals in this area, the United States must use various means; the choice of the way in which such measures are used is determined by the nature of the circumstances. Firstly, the United States should not underestimate the effect that the mere functioning of their democratic system has on 
the human rights situation in other countries. Demonstrating that both material prosperity and a democratic system are possible, the United States gives other nations an example of a great power of attraction.

Private organizations such as Amnesty International and Helsinki Watch provide another means of tracking these goals. Such organizations have access to many public media and exert considerable influence on the world opinion. Moreover, private organizations do sometimes more than the U.S. state. This usually happens in individual cases of human rights violations because nationalist regimes find it easier to give in to the pressure exerted by the world public opinion than to comply with the official requests from the government of the United States [8].

Discreet diplomacy plays an important role in the practical application of the U.S. agenda on human rights. Many times, by using the usual diplomatic channels, the United States solved individual cases of human rights violations.

Sometimes there have been positive results of the public protests and efforts against the actions of a specific oppressive regime or the overt pressure on a recalcitrant dictator. Abandoning discrete diplomacy in the U.S. relations with Ferdinand Marcos and Jean-Claude Duvalier in exchange for the use of overt pressures are good examples of this. Similarly, when necessary, the United States suspended the economic aid and the military assistance for that specific country. An even more rigorous measure is imposing economic sanctions whose severity varies depending on the situation, starting with a limited embargo and ending with a total ban on economic relations with that specific country. Another component of the U.S. policy on human rights is granting asylum to the victims of persecution.

The state must also broaden the concept of how to promote human rights. The United States has striven to eliminate certain issues related to human rights. In the fundamental sense, however, the U.S. believes that the best way to promote human rights is spreading democracy in the world.

In fact, at this level, the correlation between moral and pragmatic components of the U.S. policy on human rights is evident almost entirely. Promoting democracy and human rights abroad is not only a moral imperative, but also a strategic method of serving healthy national security interests of the United States. Obviously, between the repression and the turmoil present in other societies and the regional tensions and conflicts there is a causal link. However, in addition to purely military benefits, a world composed of democratic regimes offers an international environment that is mostly favourable to the political, economic and cultural interest of the United States. And this view is not unique in the case of the Reagan and the Bush administrations, but has been a key feature of the thinking of many American presidents, including Woodrow Wilson and Harry S. Truman [9].

IV.CREATION OF A BALANCE BETWEEN GROUP RIGHTS AND INDIVIDUAL RIGHTS

Although the policy of human rights has become an institutionalized element that was accepted in the U.S. foreign policy in the 80 's, there are still considerable problems to which a number of new problems will add in the future. Perhaps the most important problem that the authors of the American foreign policy decisions have to solve is how to promote the improvements in human rights compliance for newly created democratic societies.

While the desire to promote freedom and democracy abroad is an appropriate norm of the American state policy, the authors of such decisions should pay more attention to the fact that the American thinking on human rights may seem strange and even absurd to many cultures and societies. Here it should be noted especially that many traditional cultures of the Third World emphasize group rights (e.g. those related to religion or to commercial and industrial interests, the rights of members of the armed forces, the rights of peasants) and distinguish between these rights and individual rights.

Obviously, the United States should not impose its moral concepts anywhere by means of its own state policy. A system that works in the context of traditional political cultures and that respects the rights of groups of the people it governs and facilitates democratic elections needs support and encouragement from the United States even if it does not adhere to all the basic rules of the American democratic tradition. However, while taking into account the cultural and historical specificities of different countries, the United States can adequately pursue the establishment of common international standards on human rights as well as their acceptance by all countries. Many activists of human rights support this direction all over the world. Late Andrei Sakharov noted that "the universal character of human rights is extremely important... whose defence is an inevitable path to reuniting peoples in a turbulent world. "

The most difficult, yet necessary task is the eradication of ideological polarization that has often burdened the U.S. policy on human rights. Some people with conservative beliefs must overcome their suspicion that this policy is nothing but a liberal strategy of harassment of pro-American regimes. On the other hand, some liberals have to be convinced that the vigorous efforts to promote the cause of human rights by supporting democratic movements manifested abroad do not lack legitimacy and should not be condemned a priori [10].

To maintain a broad public and legislative support for the human rights policy, it is necessary to continually emphasize three key issues: promoting the causes related to human rights is for the national interest of the United States; it is consistent with the American traditions; and most importantly, it is a realistic effort if properly applied.

While congratulating ourselves on the fact that our world is becoming more and more democratic, we should remember that, in the past hundred years, democracy has appeared to be universally accepted several other times but then its acceptance proved to be more unreliable than we had imagined. In 1900 and 1901, a number of prestigious newspapers announced the good news that the twentieth century would be the century of democracy; in 1920, a prominent authority in the political systems wrote that democracy had no opponent [11].

Generally, a society is considered to be fully democratic 
if it has a political system that guarantees both the political rights and the civil liberties of its members. In other words, a democratic social system should not only allow people to freely choose those empowered to govern, but also guarantee the freedom of speech and the freedom of organization that make possible the existence of an effective opposition that should be capable of competing to obtain state power and even of obtaining it. Unfortunately, in most historical studies on the expansion of democracy, the emphasis tends to be placed on the existence of the electoral or legislative mechanisms that allow choice, while those liberties that make the choice be truly free are paid less attention.

Democracy, as it is known to us, has two totally different sources. The first one is the universal desire of people to be masters of their own fate or at least to have a say in choosing those who are to lead the things which have to do with their life and fate. The second source of the modern democracy is liberalism, defined as a set of beliefs, attitudes and social and political values based on the principle of universal and equal application of the law and the existence of basic human rights that are superior to those assigned to the state or the community.

In the context of this paper, the term "liberal" does not denote a particular political doctrine and is not used as an antonym of the word "conservative". It simply implies the notion that state interests cannot prevail over those of citizens[12]. Stemmed from a variety of secular and religious concepts, liberalism proclaims the fundamental value of individuals, their thoughts and desires. According to the canons of liberalism, nobody, no king and no majority has any right to tell people what to think or how to act (unless there is an imminent threat to the welfare of the society).

Liberal democracy was the one that abolished political censorship and eventually reached the impossibility to justify any kind of slavery or torture, no matter the reason or the unequal position of women and races and of ethnic minority groups. Liberal democracy is the one that is always on the verge of denying the notion that the individuals have the duty to sacrifice themselves in the service of the community should they decide that they do not wish to do so. Liberal democracy was the one that fascism and other similar ideologies tried to completely destroy; the MarxistLeninist regimes considered it so abhorrent because of its individualism and of its inherent tendency to sacrifice group interests in favour of individual's interests.

The international movement for the defence of human rights is based on the principles of liberal democracy and is a natural product of this political system. These rights have become the hope of the oppressed everywhere, and the societies that support those rights become the natural allies of all nations.

The slow pace of liberalization of democracy, even in recent years, explains why, as we move away from the present in the course of our history, the association of democracy with peace becomes increasingly unstable. Although the political systems of Athens and Sparta differed greatly, both city-states showed a strong warrior orientation; indeed, imperial wars were the specialty of Athens. For several centuries, the democratic Swiss cantons produced
Europe's mercenaries. While democracy was perfected in the West, its military forces conquered the rest of the world. War has become obsolete in the democratic West after World War I. Colonies ceased to be fashionable after World War II[13]. However, if the current democratic revolution is to make a contribution in the peacekeeping efforts around the world, this will be done only if tribe democracy is defeated by the democratic liberal attitudes that respect human rights everywhere.

Today, while we are contemplating a world in course of democratization, we must wonder how much the tribal element and the liberal element weigh within the new democratic movements. We must remember that in Italy, Japan and Germany fascism grew up in societies undergoing democratization; these societies provided the tools necessary for free speaking and small group mobilization. Those groups were then able to use these privileges in order to overthrow the democratic system by winning the sympathy and the support of the majority of people for whom the principles of liberal democracy were not firmly rooted.

According to a particular perspective, the demand of selfdetermination is a prerequisite of freedom. According to another perspective, it is a demand of independence which is unrelated to maintaining those liberties of fundamental importance in the context of liberal democracy. The demand of self-determination is too often a tribalist demand that does not result in broadening human rights but in narrowing them. It is a demand that, in a few cases, has been very close to blocking the development of democracy in the southern United States [14]. Self-determination is a legitimate right and should be treated as such as long as it does not threaten other rights. However, this right should not be confused with those fundamental civil rights which are essential in liberal democracy; in addition, it is not as important as the fundamental rights of citizens.

The fact is that we should not conclude that, because democratic movements are not, in most cases, fully animated by modern liberal ideals, we should stop our efforts to spread democracy in the world. We must continue to make efforts for several reasons. Firstly, people have the democratic rights of self-determination anyway, even if we do not like what they do with these rights. Secondly, further progress towards the democratization of the world can bring us closer to our overall goals. Thirdly, undemocratic regimes are often as illiberal as some democratic regimes. Last but not least, since in its early stages democratic systems are often more tribal than liberal, denying the right of tribal democracy may eventually lead to denying the right of a people to any kind of democracy.

\section{REFERENCES}

[1] D. Osborne, Reinventing Government, Plume, New York, 1993, pp. 97.

[2] D. Osborne, Reinventing Government, Plume, New York, 1993, pp. 128.

[3] D. Osborne, Reinventing Government, Plume, New York, 1993, pp. 207.

[4] P. Berger, The Capitalist Revolution, Basic Books, New York, 1986, pp. 83

[5] P. Berger, The Capitalist Revolution, Basic Books , New York, 1986, p. 196. 
[6] M. Barone, Our Country: The Shaping of America from Roosevelt to Reagan, Free Press, New York, 1990, pp. 55.

[7] M. Barone, Our Country: The Shaping of America from Roosevelt to Reagan, Free Press, New York, 1990, pp. 89

[8] M. Barone, Our Country: The Shaping of America from Roosevelt to Reagan, Free Press, New York, 1990, pp. 201

[9] W. C. Roof, A Generation of Seekers: The Spiritual Journeys of Baby Boom Generations, Harpercollins, New York, 1993, pp. 48.

[10] W. C. Roof, A Generation of Seekers: The Spiritual Journeys of Baby Boom Generations, Harpercollins, New York, 1993, pp. 130.

[11] P. Berger, Invitation to Sociology, Doubleday, New York, 1963, pp. 39 .

[12] P. Berger, Invitation to Sociology, Doubleday, New York, 1963, pp. 105.

[13] J. Q. Wilson, The Moral Sense, Free Press, New York, 1993, pp. 73.

[14] J. Q. Wilson, The Moral Sense, Free Press, New York, 1993, pp. 99.

[15] M. Barone, Our Country: The Shaping of America from Roosevelt to Reagan, Free Press, New York, 1990.
[16] P. Berger, Invitation to Sociology, Doubleday, New York, 1963.

[17] P. Berger, The Capitalist Revolution, Basic Books, New York, 1986.

[18] D. Osborne, Reinventing Government, Plume, New York, 1993.

[19] W. C. Roof, A Generation of Seekers: The Spiritual Journeys of Baby Boom Generations, Harpercollins, New York, 1993.

[20] J. Q. Wilson, The Moral Sense, Free Press, New York, 1993.

Alexandru Boboc-Cojocaru was born in Iasi, Romania on January 31, 1978. From 1998 to 2003, Faculty of Political Science at "Babes-Bolyai" University, Cluj-Napoca, Romania; From 2008 to 2010, Master in "International Relations" at Faculty of History in "Alexandru Ioan Cuza" University, Iasi, Romania. Alexandru is currently studying in the 3th year of $\mathrm{PhD}$ at the Faculty of History in "Alexandru Ioan Cuza" University, Iasi, Romania. Alexandru is also a teaching assistant and junior researcher at Communication Sciences Faculty in "Apollonia" University, Iasi, Romania Research interests: human rights, diplomacy, cultural conflicts. 